\title{
A Projection of the Wind Energy in the Black Sea along the $21^{\text {st }}$ Century
}

\author{
Liliana $\mathrm{Rusu}^{1, *}$ \\ ${ }^{1}$ Department of Mechanical Engineering, 'Dunarea de Jos' University of Galati, 47 Domneasca St., 800008 Galati, Romania
}

\begin{abstract}
The objective of this study is to assess the future wind power potential in the Black Sea based on the wind fields provided by the most recent regional climate projections achieved in the framework of EURO-CORDEX project. The climate change impacts on the wind speed magnitude will bring changes in the local wind power generation. From this perspective, changes in the wind power potential along the $21^{\text {st }}$ century in some reference locations of the Black Sea basin are investigated under the RCP4.5 scenario. The recent wind power conditions for a 30-year period (1976-2005) are assessed based on the results provided by the same RCM (Regional Climate Model) used to generate the future climate projections of the wind fields. The impact of the climate change on the future wind power potential is evaluated by comparisons between historical data and near-future (2021-2050) and more distant future (2071-2100) projections. Under the scenario considered, an increase of the mean wind power was observed until the middle of the $21^{\text {st }}$ century, followed by a small decrease. From the seasonal analysis resulted that, in the reference points located on the western side, the projection of the wind energy in winter time suggests an increase until the end of the century. On the other hand, the linear regressions adjusted to the annual means do not indicate a significant trend.
\end{abstract}

\section{Introduction}

In the last years, renewable power capacity installations have an increasing trend in Europe, and the wind power is one of them with the highest growing in 2017, exceeding all estimates [1]. All new wind power installations in 2017 accounted for $55.2 \%(15.6 \mathrm{GW})$, followed by solar PV with $21.5 \%$ (6 GW). In the EU, the annual increased of the wind power installations have a steady trend over the past 12 years, with three countries (Germany, Spain and UK) covering together more than half of all wind power installations [2,3].

According to a study of International Renewable Energy Agency (IRENA) [4], the role of offshore wind power in providing clean and affordable energy is also increasing due to the decrease of its levelized cost of electricity (LCOE). Besides other factors, the increase of turbine size helps the cost reductions due to the increase of the wind output. In the same study is mentioned that in the North Sea and the Atlantic Ocean are installed $90 \%$ of the global offshore wind capacity. Thus, last year in September the world's largest offshore wind farm located in the Irish Sea became operational, besides others Europe's offshore wind big capacities installed in the UK, Germany and Denmark. The expansion of this market is growing and it is moving beyond the European leaders to other continents where various countries have plans to develop their offshore wind capacities.

Although the installation of the offshore wind farms is moving nowadays farther from shore, into deeper water, in search of areas with better wind resources (water depths of up to 40 meters and as far as 80 kilometers from shore), however, there are still some limitations because the turbines are rooted in the seabed. The new technological developments of the floating offshore wind projects will induce also a new dynamics for this industrybringing an increase of the economic potential of the offshore wind technology [5]. Taking into consideration that the wind energy resources have no uniform distribution over regions or seasons, long-term evaluations of these resources in the areas of interest are absolutely necessary. Nowadays, the data regarding the wind speeds in the target areas can come from various sources. The availability of site observational data is often limited. Even when they are available, there are limitations in terms of both time and surface coverage.

The progress made in satellite measurements has led the development of the surface wind observational databases over large areas that are now increasingly used for the offshore wind power evaluations [6,7]. The development of the new computing capacities for numerical modelling is creating the possibility to be carried out long-term simulations used widely for the evaluation of the offshore wind resources [8-12]. Recently, in the context of the climate change, simulations of the future wind fields were carried out under different scenarios and various studies analyzed the impact will bring in offshore wind exploitation [13-15].

In this study, the changes in the wind power potential along the $21^{\text {st }}$ century in some reference locations of the

*Corresponding author: lrusu@ugal.ro

(c) The Authors, published by EDP Sciences. This is an open access article distributed under the terms of the Creative Commons Attribution License 4.0 (http://creativecommons.org/licenses/by/4.0/). 
Black Sea basin are investigated under RCP4.5 scenario [16]. Such greenhouse gas emission scenario corresponds to a stabilization of radiative forcing after the $21 \mathrm{st}$ century at $4.5 \mathrm{~W} / \mathrm{m}^{2}$. The impact of climate change on future wind power potential is evaluated by comparisons between historical data (1976-2005) and near-future (2021-2050) and future (2071-2100) projections

\section{Wind climate in the Black Sea}

The Black Sea is a semi-enclosed basin (Figure 1) connected to the Mediterranean Sea (Bosporus Strait) and Azov Sea (Kerch Strait). Generally, the wind features in semi-enclosed/enclosed basins are complex and high resolution wind fields (temporal and spatial resolution) are necessary for an accurate evaluation of them [17].

The wind fields simulated by the same Regional Climate Model (RCM), namely the Rossby Centre regional climate model - RCA4 model [18] from SMHI (Swedish Meteorological and Hydrologic Institute) are used in this study. These high-resolution wind fields (spatial resolution of $0.11^{\circ}$, temporal resolution 6-hour) are provided by the EURO-CORDEX database $[19,20]$, the European branch of the Coordinated Regional
Downscaling Experiment (CORDEX). The RCA4 model was forced with initial lateral boundary conditions provided by EC-EARTH Global Climate Model (GCM).

The wind fields contain information about the wind speed components at $10 \mathrm{~m}$ above the sea level ( $U_{10}$ denotes the wind speed) and three different analyses have been carried out based on them. The first analysis is related to the recent wind fields for a 30-year period (1976-2005), denoted as historical data. The second and third analyses are related to the projections of the wind fields under RCP4.5 scenario for the near-future (20212050) and future (2071-2100).

The evaluation of the wind climate is made in 20 reference points represented in Figure 1 by black circles. In the foreground, the grid points corresponding to water depths between 25-60 m are represented with red colour, the points located in depths ranging $60-95 \mathrm{~m}$ are marked with green colour, while the points corresponding to depths between 95-130 $\mathrm{m}$ are represented with yellow. The 9 reference points located in the nearshore (red zone) are noted counter-clockwise with $\mathrm{N}$, the 7 points that are in middle depth water (green zone) and the last 4 points from deeper water are noted with $\mathrm{M}$ and $\mathrm{O}$, respectively.

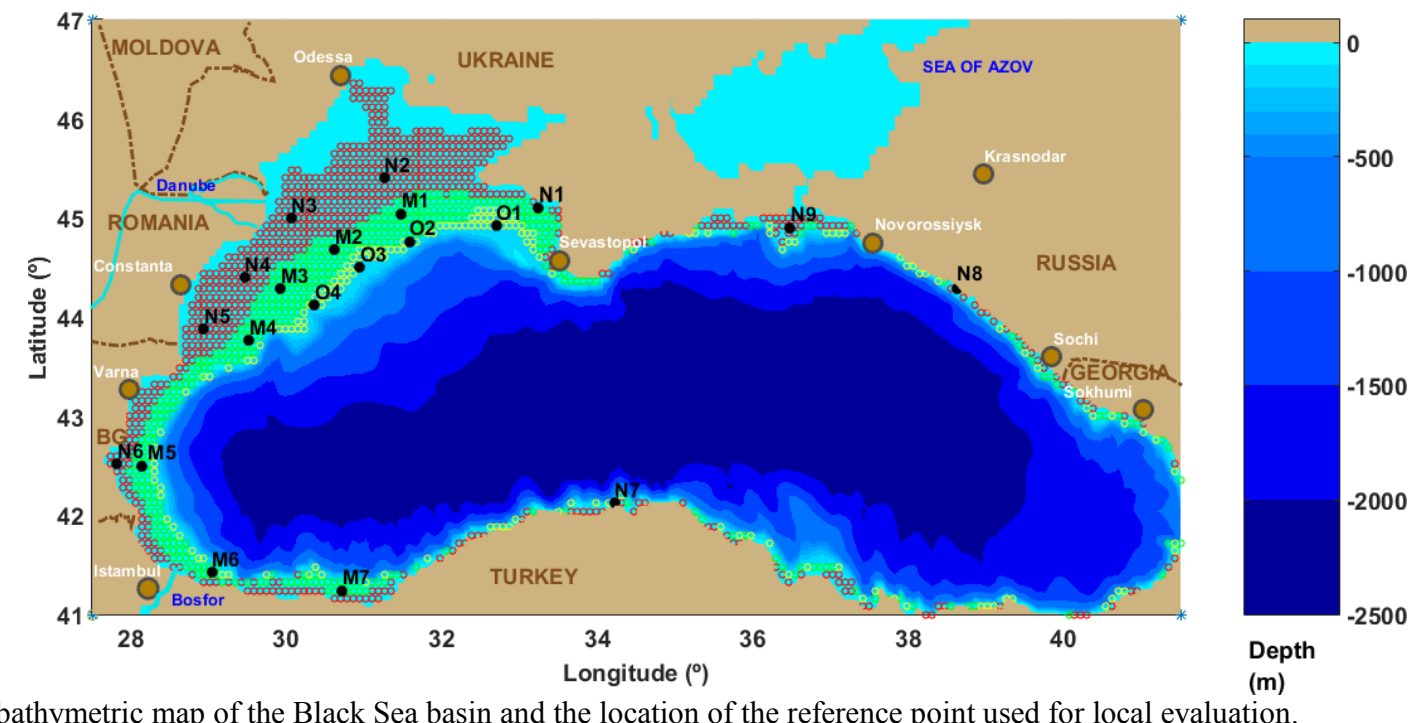

Fig. 1. The bathymetric map of the Black Sea basin and the location of the reference point used for local evaluation.

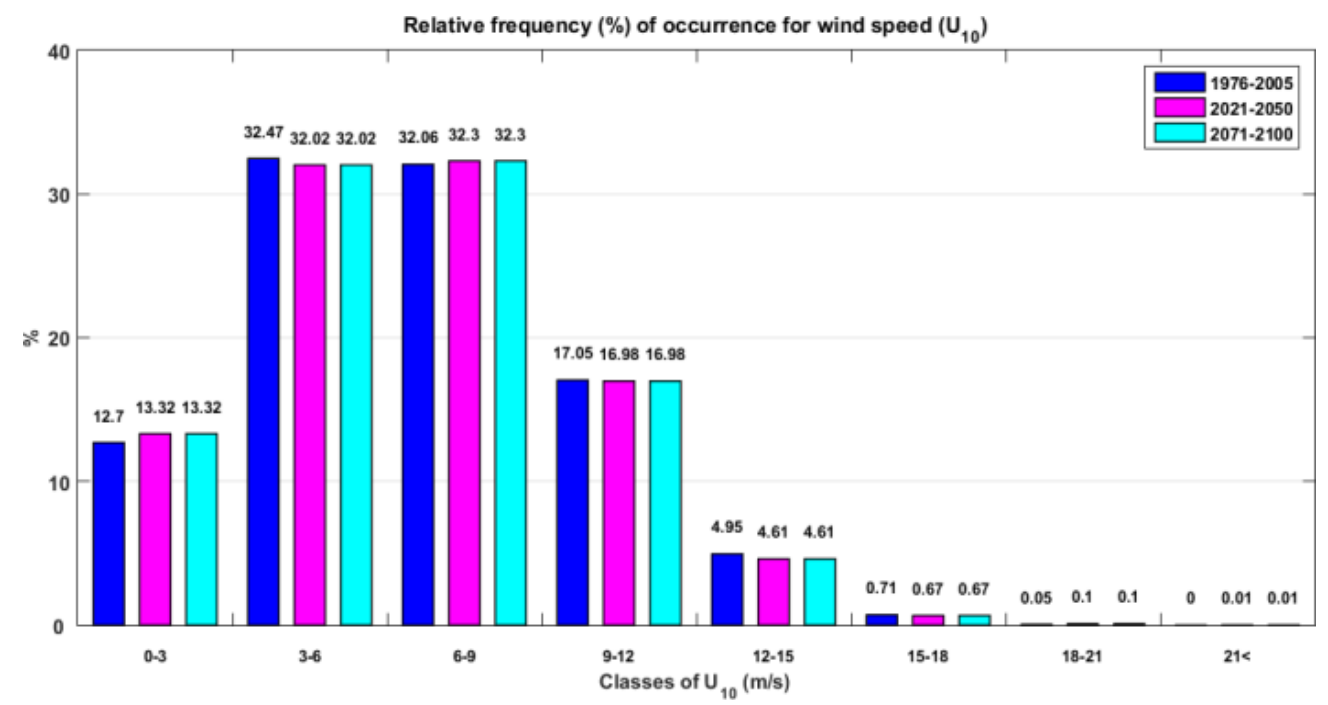

Fig. 2. Comparisons between $U_{10}$ classes simulated at the location M3 for the three 30-year time slices considered. 


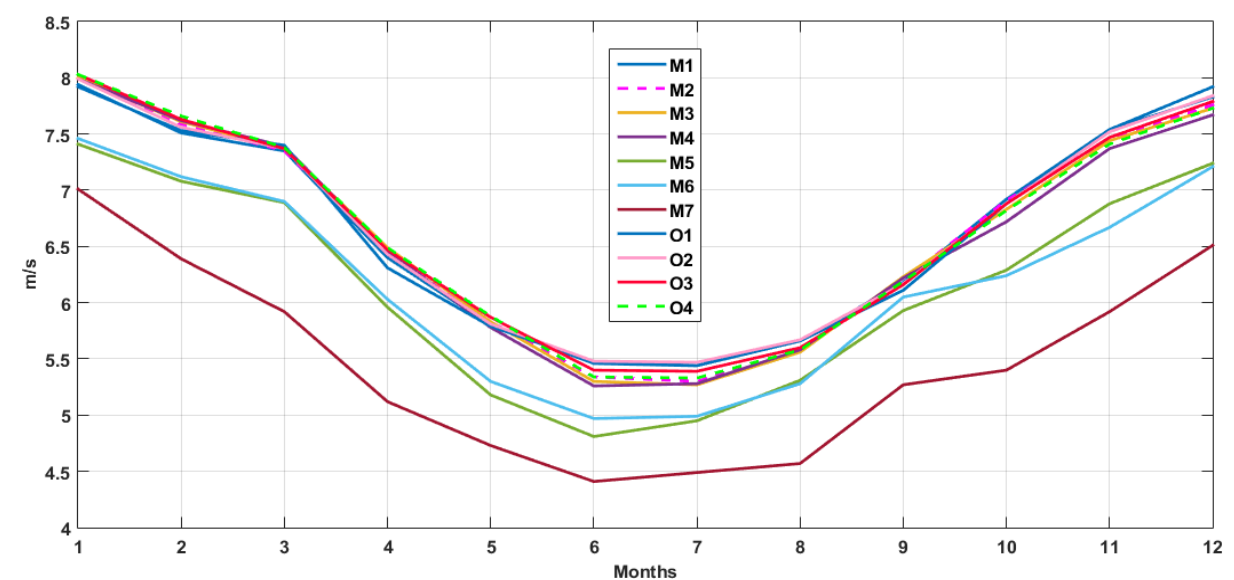

Fig. 3. Monthly variations of the $U_{10}$ means in 11 reference points located in the middle and deep water depths (denoted by $\mathrm{M}$ and $\mathrm{O}$ ) for the historical period (1976-2005).

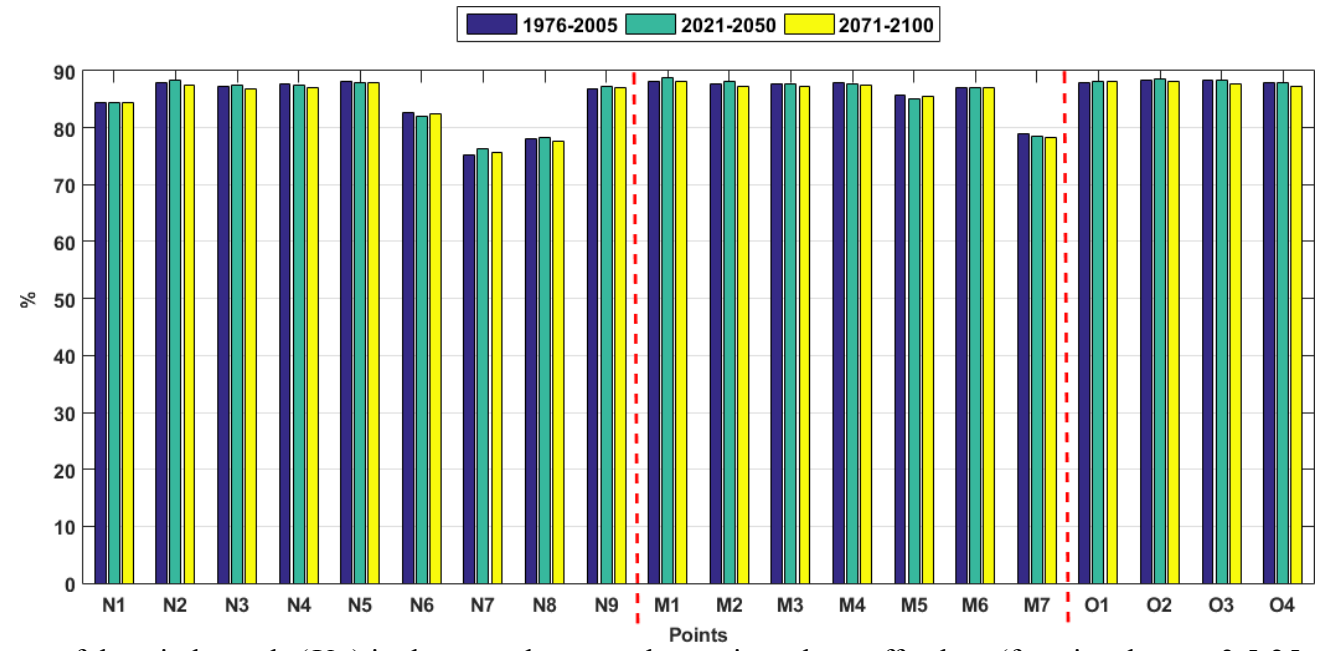

Fig. 4. Percentage of the wind speeds $\left(U_{80}\right)$ in the range between the cut-in and cut-off values (functional range $3.5-25 \mathrm{~m} / \mathrm{s}$ ) in all reference points

Figure 2 presents a comparison between the wind speeds simulated for historical period and those for nearfuture and future periods at the location M3. The comparison of the $U_{10}$ classes shows that the relative frequency of occurrences has similar values for all three periods, only for the class $0-3 \mathrm{~m} / \mathrm{s}$ higher values (about $0.6 \%$ ) there are in case of both projections, compared with historical wind speeds. The same feature was also observed in all other points (not shown here).

It is well known that in the Black Sea monthly/seasonal variability of the wind speeds exists [21]. For this reason, an evaluation of the monthly variation of the $U_{10}$ means was made. In Figure 3 the graphs corresponding to the points located in the middle and deep water depths (11 points) are represented for the historical period (1976-2005).

From Figure 2 it can be observed that in the months December and January the $U_{10}$ means are around 7.5-8 $\mathrm{m} / \mathrm{s}$ in all points (except in M7), while in summer June and July the means are between $4.5-5 \mathrm{~m} / \mathrm{s}$.

\section{Assessment of the wind power}

The wind power density $P\left(\mathrm{~W} / \mathrm{m}^{2}\right)$ per unit of the swept area is computed based on the information regarding the wind speed using the relationship [22]:

$$
P=\frac{1}{2} \rho_{\text {air }} U_{z}^{3}
$$

with $\rho_{\text {air }}$ the air density has the value of $1.225 \mathrm{~kg} / \mathrm{m} 3$ and $U_{\mathrm{z}}$ being the wind speed at a height $z$.

Because the wind speed at a height of $10 \mathrm{~m}$ over the sea level is usually provided by databases, it will be necessary to extrapolate it at the height where the wind turbines are estimated to operate. In the last years, the typical height for offshore wind exploitation has grown at around $80 \mathrm{~m} \mathrm{[23].} \mathrm{The} \mathrm{wind} \mathrm{speed} \mathrm{at} \mathrm{a} \mathrm{high} \mathrm{level} \mathrm{can} \mathrm{be}$ computed using a logarithmic law [24]. This approach established that the wind speed $U_{\mathrm{z}}$ (in the present case $z$ is considered to be $80 \mathrm{~m}$ ) can be expressed as:

$$
U_{z}=U_{z r e f} \frac{\ln \left(z / z_{0}\right)}{\ln \left(z_{\text {ref }} / z_{0}\right)}
$$

where $U_{\text {zref }}$ is, in fact, the known wind speed $U_{10}$ at the height $z_{\text {ref }}$ (in this case $10 \mathrm{~m}$ ), while the value of the sea surface roughness length $z_{0}$ is taken $0.0002 \mathrm{~m}$ over the sea.

Based on time series of wind speed $U_{10}$ available in each reference point, $U_{80}$ and the correspondent power density $P$ are computed. In this way, for each reference point, three time series of $U_{80}$ and $P$ have resulted, corresponding to the three 30 -year periods considered in this study. Depending on the wind turbine characteristics, the electrical power is produced only for a range of wind 
speeds defined by the cut-in and cut-off values that in general are ranging between $3.5-25 \mathrm{~m} / \mathrm{s}$ [25].

Considering the $U_{80}$ values, the percentage of the wind speeds inside the functional range conditions was computed in all reference points and Figure 4 shows the results obtained. As expected, the highest percentages are in all points located in deep water (higher than $85 \%$ ), but in some other points comparable percentages can be found (e.g. N2-N5 and M1-M5). However, must be highlighted that all these points are located in the western part of the Black Sea basin.

The next of the wind power analysis is represented by the evaluation of the same statistical parameters that will give us an indication of the wind power potential in the target area. The statistical parameters considered are: Mean - mean value, Max - maximum value, Std standard deviation, $50^{\text {th }}$ and $95^{\text {th }}$ percentiles and they were computed based on their standard definitions. The results obtained for mean and standard deviation are presented in Figure 5, while those related to $50^{\text {th }}$ and $95^{\text {th }}$ percentiles in Figure 6. For some selected reference points these statistics can be found also in Table 1 .

The identification of some trends existing in wind power evolution is also important. This can be observed using the annual means of the wind power, some results are presented in Figure 7 for the point M3.
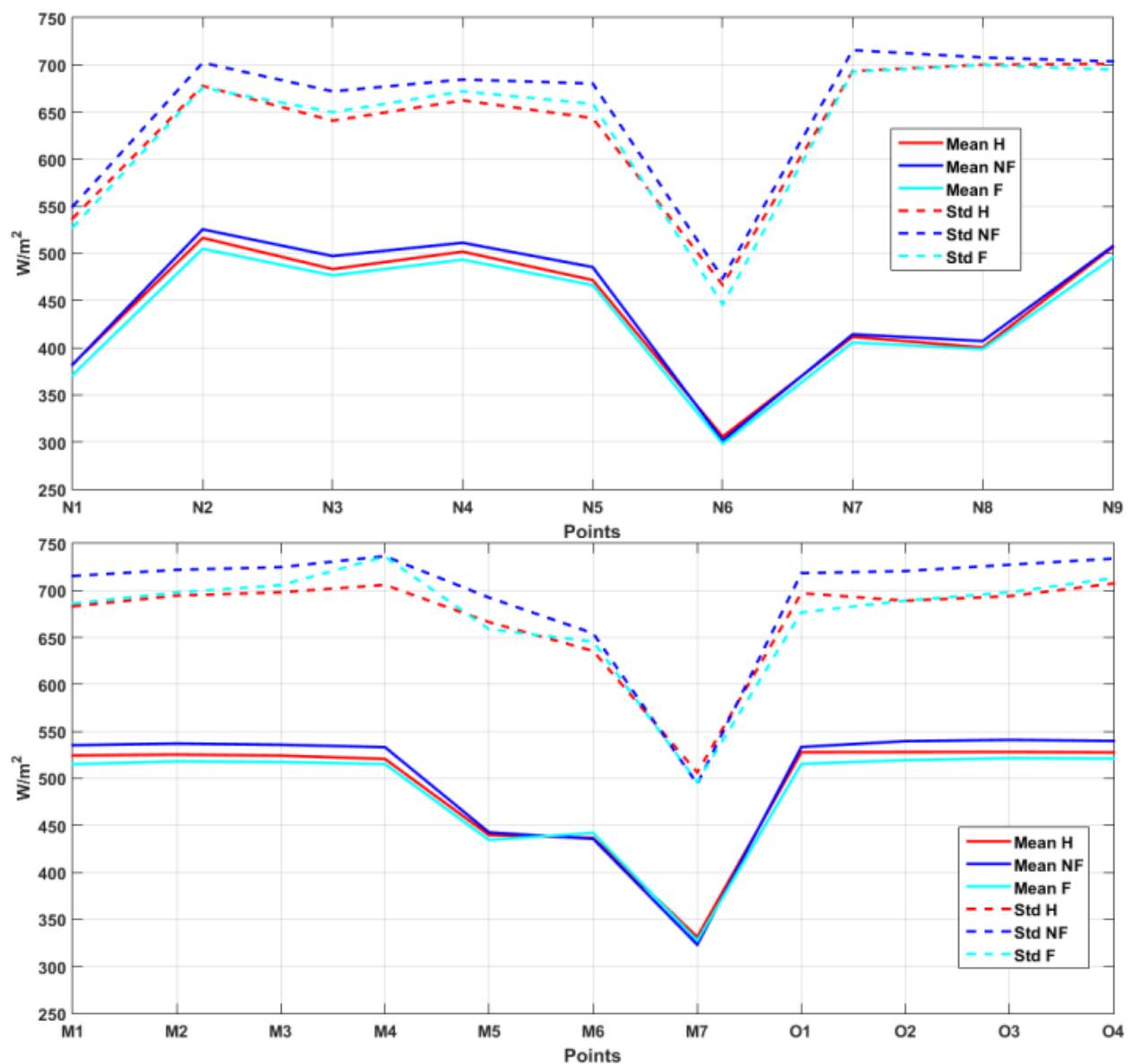

Fig. 5. Comparisons between mean (Mean) and standard deviation (Std) wind power in the reference points at $80 \mathrm{~m}$, for historical (H), near future (NF) and future (F) periods.

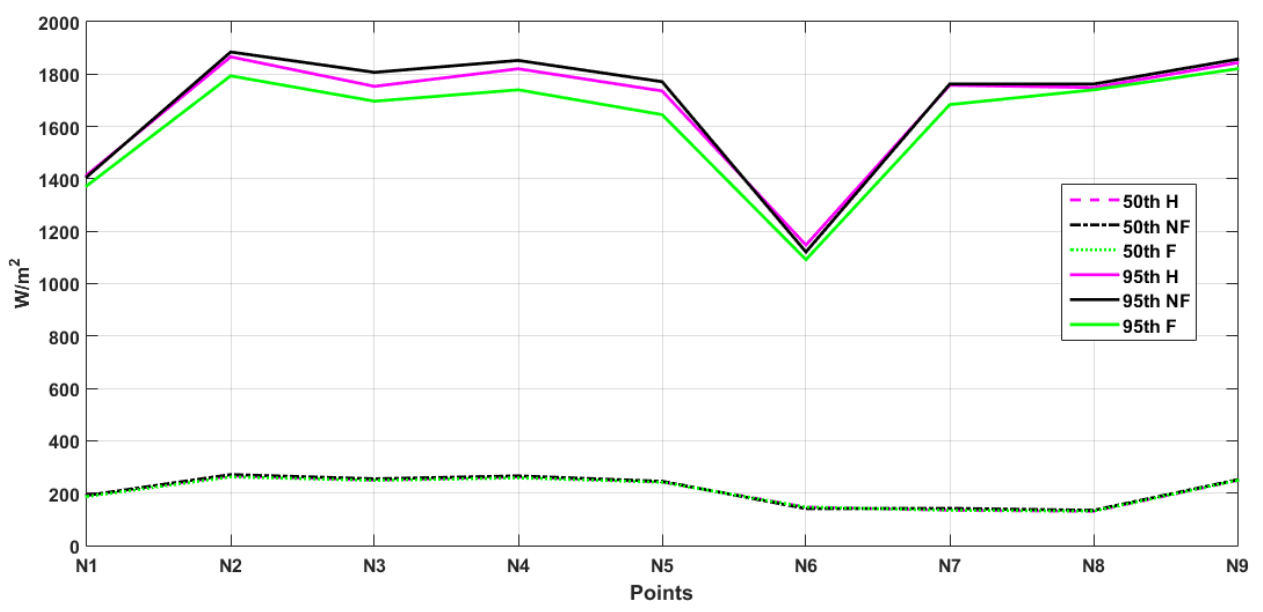




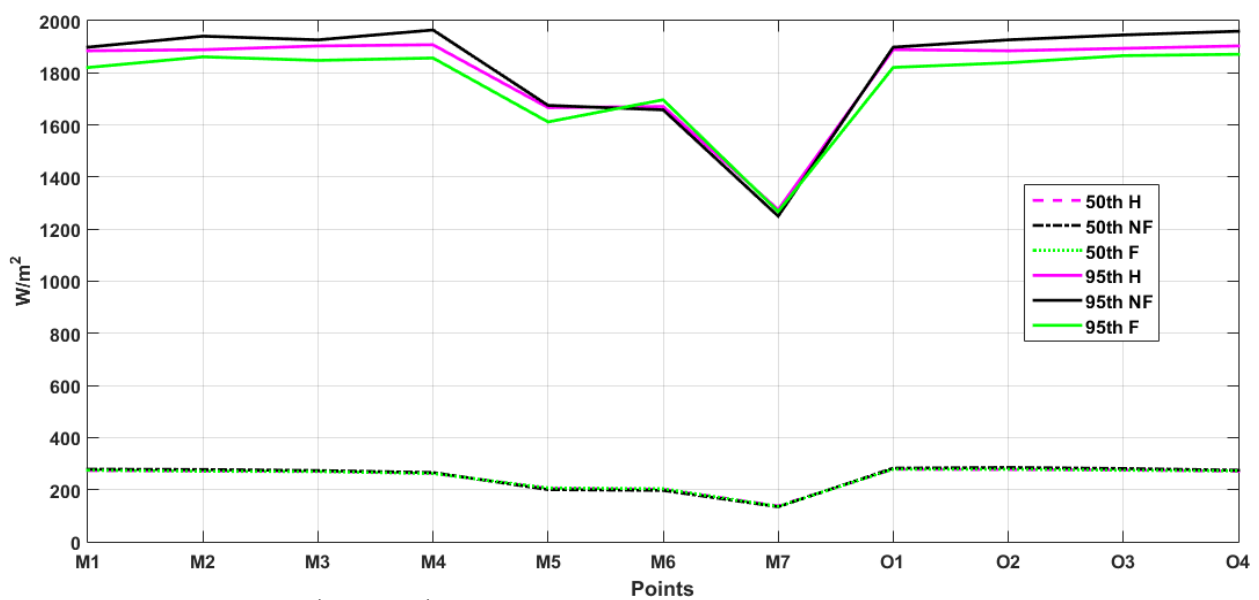

Fig. 6. Comparisons between the mean $50^{\text {th }}$ and $95^{\text {th }}$ percentiles of wind power computed in the reference points at the hub height of 80 $\mathrm{m}$, historical $(\mathrm{H})$, near future $(\mathrm{NF})$ and future $(\mathrm{F})$ periods.

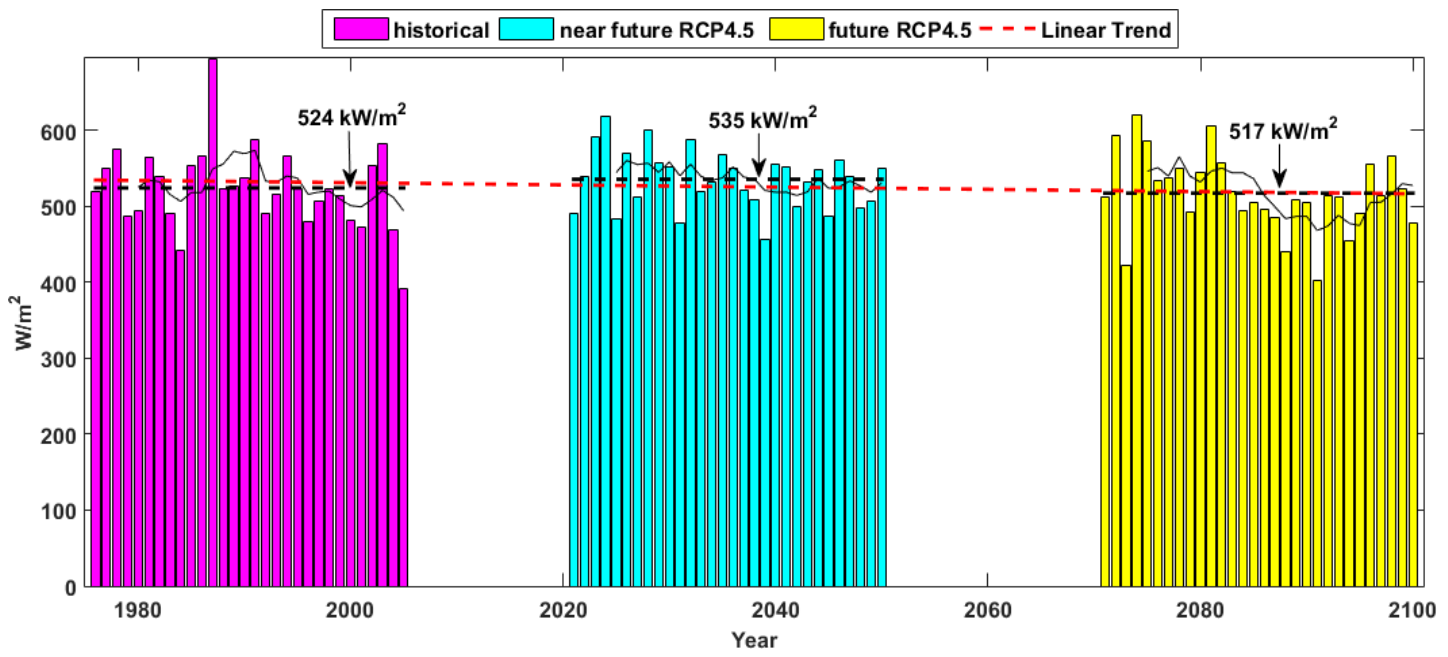

Fig. 7. Annual means of the wind power at the height of $80 \mathrm{~m}$ above the sea level for the point $\mathrm{M} 3$ computed for historical data and, near future and distant future projections under RCP4.5 scenario. The linear trend is indicated by the red dashed line.

The highest mean values of the wind power there are in all deep water points, for all time periods considered, with values ranging between $500-550 \mathrm{~W} / \mathrm{m}^{2}$. The same feature is maintained for the points M1-M4 located in middle depths. As regards the nearshore points, only in the locations $\mathrm{N} 2, \mathrm{~N} 4$ and $\mathrm{N} 9$ are reached values around $500 \mathrm{~W} / \mathrm{m}^{2}$. The standard deviations have the highest values in the same point as the means (about $700 \mathrm{~W} / \mathrm{m}^{2}$ ).

Table 1. Wind power characteristics in some reference points at $80 \mathrm{~m}$ for historical $(\mathrm{H})$, near future $(\mathrm{NF})$ and future $(\mathrm{F})$ periods.

\begin{tabular}{|c|c|c|c|c|c|c|}
\hline \multicolumn{2}{|c|}{ Points } & $\begin{array}{c}\text { Mean } \\
\left(\mathbf{W} / \mathbf{m}^{2}\right)\end{array}$ & $\begin{array}{c}\text { Max } \\
\left(\mathbf{W} / \mathbf{m}^{\mathbf{2}}\right)\end{array}$ & $\begin{array}{c}\text { Std } \\
\left(\mathbf{W} / \mathbf{m}^{2}\right)\end{array}$ & $\begin{array}{c}\mathbf{5 0}^{\text {th }} \\
\left(\mathbf{W} / \mathbf{m}^{2}\right)\end{array}$ & $\begin{array}{c}\mathbf{9 5}^{\text {th }} \\
\left(\mathbf{W} / \mathbf{m}^{2}\right)\end{array}$ \\
\hline \multirow{4}{*}{ H } & N2 & 516 & 9112 & 677 & 265 & 1866 \\
& M1 & 524 & 8340 & 683 & 273 & 1880 \\
& O2 & 528 & 8503 & 689 & 277 & 1884 \\
\hline \multirow{4}{*}{ NF } & N2 & 525 & 10649 & 702 & 270 & 1884 \\
& M1 & 535 & 13417 & 715 & 278 & 1898 \\
& O2 & 540 & 13555 & 720 & 285 & 1926 \\
\hline \multirow{4}{*}{ F } & N2 & 504 & 12693 & 675 & 262 & 1793 \\
& M1 & 515 & 12909 & 686 & 274 & 1820 \\
& O2 & 519 & 13728 & 689 & 278 & 1838 \\
\hline \multirow{4}{*}{ H } & N3 & 483 & 7767 & 641 & 250 & 1753 \\
& M2 & 525 & 9152 & 694 & 272 & 1888 \\
& O3 & 528 & 9639 & 694 & 276 & 1893 \\
\hline
\end{tabular}

\begin{tabular}{|c|c|c|c|c|c|c|}
\hline & N3 & 497 & 10502 & 671 & 254 & 1806 \\
NF & M2 & 537 & 12140 & 721 & 277 & 1940 \\
& O3 & 540 & 12349 & 727 & 281 & 1945 \\
\hline \multirow{4}{*}{ F } & N3 & 476 & 13027 & 649 & 248 & 1696 \\
& M2 & 518 & 12012 & 697 & 271 & 1861 \\
& O3 & 521 & 12044 & 698 & 274 & 1866 \\
\hline \multirow{4}{*}{ H } & N4 & 501 & 8093 & 662 & 261 & 1820 \\
& M3 & 524 & 10693 & 698 & 270 & 1902 \\
& O4 & 527 & 15151 & 707 & 270 & 1903 \\
\hline \multirow{4}{*}{ NF } & N4 & 511 & 9099 & 684 & 265 & 1852 \\
& M3 & 535 & 10546 & 724 & 273 & 1926 \\
& O4 & 539 & 15375 & 733 & 274 & 1959 \\
\hline \multirow{4}{*}{ F } & N4 & 493 & 21749 & 672 & 258 & 1740 \\
& M3 & 517 & 15849 & 706 & 269 & 1847 \\
& O4 & 521 & 17148 & 713 & 272 & 1871 \\
\hline
\end{tabular}

The $50^{\text {th }}$ percentile values illustrated in Figure 6 are ranging between $150-300 \mathrm{~W} / \mathrm{m}^{2}$ for all reference points and time periods. Between the $95^{\text {th }}$ percentile values computed in the reference points are higher differences. Thus, values around $1900 \mathrm{~W} / \mathrm{m}^{2}$ are found at all points denoted by $\mathrm{O}$, for the points from $\mathrm{M} 1$ to $\mathrm{M} 4$, and also in $\mathrm{N} 2$. In the points from $\mathrm{N} 3$ to $\mathrm{N} 5$, these values are in the range $1600-1800 \mathrm{~W} / \mathrm{m}^{2}$, while in all other points $95^{\text {th }}$ are lower than $1600 \mathrm{~W} / \mathrm{m}^{2}$. No significant differences 
between the $95^{\text {th }}$ percentiles computed for different time periods were observed.

The evolution of the statistical parameters from nearshore to deep water is more evident analyzing the values presented in Table 1 , for the points located along a perpendicular to the shore. Small differences are between the values in $\mathrm{M}$ and $\mathrm{O}$ points, while those between $\mathrm{N}$ and $\mathrm{M}$ points are greater.

The annual means of the wind power presented in Figure 7, and also the wind power mean computed for each 30-year time period (dashed black line), indicate that until the middle of the $21^{\text {st }}$ century an increase of the wind energy will occur under RCP4.5 scenario. After this, a very small decrease in the mean wind power over the period 2071-2110 (about 3\% in relation to 20212050 ) is projected. This evolution is also indicated by the linear trend fitted to the annual means. From the seasonal analysis of the mean wind power in each point it was observed (not shown here) that, especially in nearshore points, all the mean wind power projections computed for summer time are smaller than the values computed for historical data.

\section{Conclusions}

In the present work, an analysis of the wind climate and wind power potential in the Black Sea was carried out. This was focused on the evaluation of the main changes expected to occur along the $21^{\text {st }}$ century. Some reference locations were considered for this analysis.

The wind energy resources for three-time intervals were evaluated, each one covering a 30-year period: historical data (1976-2005), near-future (2021-2050) and more distant future (2071-2100) projections, respectively.

Following the results of the analysis, under the RCP4.5 scenario, an increase of the mean wind power was observed until the middle of the $21^{\text {st }}$ century, followed by a small decrease. This decrease seems to be induced especially by the decrease of the wind power in the summer time. The linear regressions adjusted to the annual means do not indicate a significant trend.

\section{Acknowledgment}

This work was carried out in the framework of the research project REMARC (Renewable Energy extraction in MARine environment and its Coastal impact), supported by the Romanian Executive Agency for Higher Education, Research, Development and Innovation Funding - UEFISCDI, grant number PN-III-P4IDPCE-2016-0017.

The wind data used in this study have been obtained from the EURO-CORDEX data servers.

\section{References}

1. GWEC, Global Wind Report-Annual Market Update 2017 (2018) https://gwec.net/publications/globalwind-report-2/

2. WindEurope, Breaking new ground, Report September (2018) https://windeurope.org/aboutwind/reports/breaking-new-ground/
3. WindEurope, Offshore Wind in 2017, February (2018) https://windeurope.org/wpcontent/uploads/files/about-

wind/statistics/WindEurope-Annual-OffshoreStatistics-2017.pdf

4. IRENA, Offshore innovation widens renewable energy options: Opportunities, challenges and the vital role of international co-operation to spur the global energy transformation (Brief to G7 policy makers), International Renewable Energy Agency, Abu Dhabi (2018)

5. N. Bento, M. Fontes, Emergence of floating offshore wind energy: Technology and industry, Renewable and Sustainable Energy Reviews 99, 66-82 (2019) https://doi.org/10.1016/j.rser.2018.09.035

6. S.B. Capps, C.S. Zender, Estimated global ocean wind power potential from QuikSCAT observations, accounting for turbine characteristics and siting, Journal of Geophysical Research: Atmospheres, 115 (D9) (2010) https://doi.org/10.1029/2009JD012679

7. A. Raileanu, F. Onea, E. Rusu, Evaluation of the offshore wind resources in the european seas based on satellite measurements, Energy and Clean Technologies, International Multidisciplinary Scientific GeoConference-SGEM, 227-234 (2015) http://doi.org/10.5593/SGEM2015/B41/S17.030

8. F. Onea, L. Deleanu, L. Rusu, C. Georgescu, Evaluation of the wind energy potential along the Mediterranean Sea coasts, Energy Exploration \& Exploitation, $34 \quad$ (5), 766-792 (2016) http://dx.doi.org/10.1177/0144598716659592

9. M.G. Sotillo, R. Aznar, F. Valero, The 44-year Mediterranean HIPOCAS wind database: A useful tool to analyse offshore extreme wind events from a long-term regional perspective, Coastal Engineering $55 \quad$ (11), $\quad 930-943 \quad$ (2008) https://doi.org/10.1016/j.coastaleng.2008.02.008

10. F. Onea, E. Rusu, Efficiency assessments for some state of the art wind turbines in the coastal environments of the Black and the Caspian seas, Energy Exploration \& Exploitation 34(2), 217-234 (2016) https://doi.org/10.1177/0144598716629872

11. L. Rusu, P. Pilar, C. Guedes Soares, Reanalysis of the Wave Conditions in the Approaches to the Portuguese Port of Sines, Maritime Transportation and Exploitation of Ocean and Coastal Resources, Editors Taylor \& Francis, London, Vol II, 1137-1142 (2005).

12. F. Onea, A. Raileanu, E. Rusu, Evaluation of the Wind Energy Potential in the Coastal Environment of Two Enclosed Seas, Advances in Meteorology, Article Number: 808617 http://dx.doi.org/10.1155/2015/808617

13. J. Moemken, M. Reyers, H. Feldmann, J.G. Pinto, Future changes of wind speed and wind energy potentials in EURO- CORDEX ensemble simulations, Journal of Geophysical Research: Atmosphere https://doi.org/10.1029/2018JD028473. 
14. D. Ganea, E. Mereuta, L. Rusu, L., Estimation of the Near Future Wind Power Potential in the Black Sea, Energies 11(11), AN 3198, (20180 https://doi.org/10.3390/en11113198

15. J. Weber, J. Wohland, M. Reyers, J. Moemken, C. Hoppe, J.G. Pinto, D. Witthaut, Impact of climate change on backup energy and storage needs in winddominated power systems in Europe, PloS one 13(8), p.e0201457

(2018) https://doi.org/10.1371/journal.pone.0201457

16. R.H. Moss, J.A. Edmonds, K.A. Hibbard, M.R. Manning, S.K. Rose, et al., The next generation of scenarios for climate change research and assessment, Nature 463(7282), 747-756 (2010) https://doi.org/10.1038/nature08823

17. L. Rusu, M. Bernardino, C. Guedes Soares, Influence of Wind Resolution on the Prediction of Waves Generated in an Estuary, Journal of Coastal Research SI 56, 1419-1423 (2009) http://egeo.fcsh.unl.pt/ICS2009/ docs/ICS2009 Volume_II/ 1419.1423_L.Rusu_ICS2009.pdf

18. E. Kjellström, L. Bärring, G. Nikulin, C. Nilsson, G. Persson, G. Strandberg, Production and use of regional climate model projections - A Swedish perspective on building climate services, Climate services 2, 15-29 (2016)

19. EURO - CORDEX Guidelines. Available online: http://www.euro- cordex.net/imperia/md/content/csc/cordex/eurocordex-guidelines-version1.0-2017.08.pdf

20. D. Jacob, J. Petersen, B. Eggert, A. Alias, O.B. Christensen, et al., EURO-CORDEX: new highresolution climate change projections for European impact research, Reg Environ Change 14, 563-578 (2014) doi:10.1007/s10113-013-0499-2.

21. L. Rusu, A.B. Raileanu, F. Onea, A comparative analysis of the wind and wave climate in the Black Sea along the shipping routes, Water 10(7), AN 924 (2018) https://doi.org/10.3390/w10070924

22. G. Boyle, Renewable energy: power for a sustainable future, Oxford University Press (1996)

23. A. Colmenar-Santos, J. Perera-Perez, D. Borge-Diez, Offshore wind energy: A review of the current status, challenges and future development in Spain, Renewable and Sustainable Energy Reviews 64, 1-18 (2016).

24. R. Stull, Practical Meteorology: an Algebra Based Survey of Atmospheric Science, Univ British Columbia, Canada (2016)

25. Onea, F., Rusu, L., Evaluation of Some State-OfThe-Art Wind Technologies in the Nearshore of the Black Sea, Energies 11(9), $2452 \quad$ (2018) https://doi.org/10.3390/en11092452 